\title{
El régimen económico del matrimonio en la sociedad valenciana tardomedieval. \\ La «germanía» o comunidad de bienes en las comarcas meridionales, 1421-1531*
}

\author{
The economic regimen of the marriage in Valencia at the \\ end of the Middle Age. The commonwealth in the southern \\ regions, 1421-1531
}

JAIME PIQUERAS JUAN**

\begin{abstract}
RESUMEN
ABSTRACT

En el reino medieval de Valencia coexistieron dos modalidades de régimen económico matrimonial, el sistema dotal, de mayoritaria aceptación y detalladamente regulado en el cuerpo legal que constituyeron los «furs", mediante el cual, las esposas mantenían la titularidad del patrimonio aportado por sus familias en el momento de contraer nupcias y el sistema de comunidad de bienes o "germanía», por el que ambos cónyuges constituían un patrimonio común. El presente artículo se centra en definir, cuantificar y explicar el comportamiento específico que se observa respecto de la elección de régimen económico matrimonial en las comunidades urbanas de los territorios del sur valenciano durante el periodo final de

la Edad Media. Para ello se analiza la implantación, organización e impacto de la

In the medieval kingdom of Valencia coexisted two matrimonial economic system modalities, the «dotal» system, of majority acceptance and regulated in detail in the legal code of the "furs", through which the wives kept the ownership of the patrimony given by her families in the moment of contracting nuptials and the community of properties system or «germania», through which both spouses constituted a common wealth. The present article centers on defining, quantifying and to explain the specific behaviour that is observed with regards to the matrimonial economic system choice in the urban communities on the Valencian south during the final period of the Middle Age. To do so the implementation is analyzed organization and impact of the textile industry in these regions, establishing relationships between the
\end{abstract}

* Fecha de recepción del artículo: 2009-10-8. Fecha de aceptación del artículo: 2009-12-30.

** Doctor en Historia (Medieval) por la UNED. C.e.: roures@ servicam.com 
manufactura textil en estas comarcas, estableciéndose relaciones entre régimen económico matrimonial y nivel y actividad socio profesional.

\section{PALABRAS CLAVE}

Historia Medieval, Reino de Valencia,

Matrimonio, régimen económico, germanía, manufactura textil, sur de

Valencia. marriage economic system and the socioprofessional activity status.

\section{KEY WORDS}

Medieval History, Kingdom of Valencia, marriage, economic system, germania, textile industry, Valencian south.

\section{A Jaume y Francesc}

En la actualidad, la formulación del derecho matrimonial en el reino medieval de Valencia es bien conocida en todas sus disposiciones, gracias a los trabajos que desde la primera mitad del s. XX han venido realizándose por diversos autores $^{1}$. La recuperación de los textos legales medievales valencianos, junto a sus posteriores ampliaciones, ha resultado determinante para conocer cómo se organizó por el poder político el complejo entramado de acciones que, mediante la regulación de las uniones matrimoniales y en combinación con el derecho de sucesiones, conducía a la transmisión de bienes y valores a las nuevas generaciones de forma normalizada, estableciéndose así las bases para la reproducción de las estructuras fundamentales de la sociedad en el tiempo.

En el caso valenciano se configuró, en lo relativo al régimen económico del matrimonio, un sistema dual en el que se podía optar entre una modalidad en la que la esposa mantenía la titularidad de la dote que en su momento se aportó por su familia, además de sus propios bienes privativos, o bien elegir un tipo de comunidad de bienes en la que ambos cónyuges aportaban los bienes procedentes de las donaciones hechas por sus respectivas familias a un patrimonio común. El sistema dotal, una separación de bienes matizada, fue primado por la legislación medieval valenciana, se halla profusamente regulado en todos sus aspectos y constituyó el tipo de matrimonio que más difusión alcanzó, hasta la abolición de la legislación foral en $1707^{2}$. Por el contrario, la opción por el régimen económico matrimonial de "germanía", o comunidad de bienes, solo es citada en dos ocasiones ${ }^{3}$ en todo el cuerpo legal que constituyen los «furs" y ha sido considerada como de uso mino-

1 Sobre el conjunto de normativa foral medieval valenciana: CHABÁS, R.: Génesis del derecho foral valenciano.(1902) Ed. Mateu Rodrigo. Valencia, 1995. La recopilación sobre la que se ha trabajado en esta investigación ha sido la de COLÓN, G. y GARCÍA, A.:Furs de València. Ed. Barcino. Barcelona, 2002. Sobre la problemática de la regulación legal de los matrimonios y, en concreto sobre la comunidad de bienes o «germania» véase GARCÍA, H.: «La Germania». Boletín de la Sociedad Castellonense de Cultura, $n .{ }^{\circ}$ 9. 1928, pp 76-79. Y también GARCíA, H.: «Más sobre la Germania». Boletín de la Sociedad Castellonense de Cultura, $n .{ }^{\circ}$ 10. 1929, pp. 23-30. 
ritario y marginal. Debemos señalar que esta situación general tiene, cuando menos, una notable excepción.

El objeto del presente artículo es dar a conocer la investigación llevada a cabo recientemente, bajo la forma de tesis doctoral, sobre la aplicación práctica de las mencionadas disposiciones legales; es decir, se ha tratado de determinar mediante la observación de un número significativo de documentos de aplicación del derecho generados por un conjunto social concreto, si se respetaron o no en cada momento las normas legales vigentes en el campo del derecho matrimonial, y, más concretamente, en el aspecto de la opción y forma de aplicación del régimen económico del matrimonio. El grupo social estudiado corresponde a las comunidades del área sur e interior del reino de Valencia, que comprende actualmente una parte del sur de la provincia de Valencia y el norte de la de Alicante, siendo los núcleos urbanos más significativos representados en este trabajo los de Alcoy, Bocairent, Banyeres de Mariola y Cocentaina, existiendo presencia de actos jurídicos realizados en otras localidades del área ${ }^{4}$.

El interés que presenta este tema, a pesar de lo específico y limitado del alcance de esta investigación, circunscrita a una parte definida del reino medieval de Valencia, radica en las diversas lecturas que la historiografía reciente da al hecho matrimonial o a aquello que en otros términos se ha definido como «nupcialidad» en un sentido extenso, no exclusivamente demográfico. En el campo de la Historia del Derecho se ha considerado necesaria una revisión desde los documentos de aplicación práctica, del derecho dimanante de los códigos legales medievales, así como el estudio del nivel y forma de aplicación de las normativas matrimoniales, de forma que se puedan apreciar desviaciones o resistencias que informen sobre aspectos relevantes de las sociedades donde se producen. Igualmente, la Historia Social, en su concepción más amplia, no ha dejado de interesarse por las relaciones y consecuencias que ha tenido el matrimonio para la sociedad, sin olvidar los trabajos que se han ocupado de esta faceta de la vida en los grupos marginados y minoritarios como por ejemplo, la minoría mudéjar en los reinos peninsulares medievales. Por otra parte, existe una corriente cada vez más relevante del pensamiento histórico, estrechamente vinculada a la antropología social y que está interesada en los lazos que unen las formas que presenta el matrimonio y la familia con las realidades económicas de las sociedades medievales europeas. ${ }^{5}$

2 BELDA SOLER, M.A.: El régimen matrimonial de bienes en los «Furs de València» Ed. Cosmos. Valencia, 1966. Pg. 43. La autora hace referencia a la pronta aceptación por la sociedad valenciana de régimen matrimonial dotal, debiéndose señalar que tal aceptación la circunscribe al ámbito de la ciudad de Valencia, sin hacerla extensiva expresamente al resto del reino valenciano.

3 «Fur»IV, II, 5 y «Fur» X, VI, 6. COLÓN, G. y GARCÍA, A.: Op. Cit.

4 Ver anexo sobre fuentes documentales al final del artículo.

${ }^{5}$ La autora más representativa del grupo que desde la $H .{ }^{a}$ del Derecho ha trabajado la línea de observación de los documentos de aplicación del derecho es GUILLOT ALIAGA, D.:El régimen económico del matrimonio en la Valencia foral.Biblioteca Valenciana. Generalitat Valenciana. Valencia, 2002.Los principales trabajos que se han ocupado del tema matrimonial desde perspectivas más generales para el área de Valencia son los de FURIÓ, A.:Camperols del País Valencià.. Col.lecció Politècnica, 3. Diputación de Valencia, 1982 y TORRÓ ABAD, J.: La formació d'un espai feudal. Alcoi de 1245 a 1305. Diputación 
En el caso del reino medieval de Valencia, se estableció en el código normativo que constituyen los «Furs" y desde fechas muy tempranas, un sistema predominante de régimen económico matrimonial basado en la separación de bienes entre los cónyuges, el régimen dotal, en el que la esposa mantenía la titularidad de la dote aportada por su familia en el momento de la boda, junto a una aportación o «creix» que el esposo hacía, siempre que la novia accediera virgen al matrimonio. Al margen de la titularidad de la dote y del "creix», los bienes que pudiera poseer con anterioridad al matrimonio o los que recibiera o adquiriera durante el mismo, permanecían como patrimonio privativo de la esposa, consistiendo por lo tanto, su aportación al mantenimiento de la familia, en el conjunto que representaba la dote y el "creix», existiendo una serie de supuestos en los que la esposa podía instar legalmente la restitución por el marido de esas cantidades. Este sistema, similar en sus aspectos básicos a otros contemporáneos en Europa Occidental ${ }^{6}$, articuló las relaciones matrimoniales en el nuevo reino conviviendo durante siglos con otro basado en la comunidad de bienes entre los cónyuges, la "germanía», de origen discutido ${ }^{7}$ y que fue contemplada por el legislador como una opción secundaria y destinada a desaparecer, tal y como su prácticamente inexistente regulación legal parece indicar. Por lo tanto, las parejas y sus familiares, a la hora de planificar y negociar el conjunto de transacciones económicas que constituían el matrimonio, podían optar en el ámbito valenciano, bien por un sistema que garantizaba a la esposa un patrimonio propio e independiente de los bienes del marido; este sistema requería de cuantificaciones y cálculos y obligaba en la mayoría de casos al pago o establecimiento de garantías por parte del novio, por importe equivalente a la mitad de la dote de la novia; o bien, por un régimen de comunidad de bienes que consistió en la formación de un único patrimonio que comprendía todos los bienes aportados por los dos novios a la hora del matrimonio, bienes que recibían ambos de sus parientes y valedores mediante la figura jurídica de "donatio inter vivos" con anterioridad a la formulación del matrimonio. Un sistema este último, en principio mucho más sencillo y con un inferior potencial de conflicto a la hora de aplicar el derecho de sucesiones por fallecimiento de uno de los cónyuges.

Respecto de las consecuencias prácticas que la opción por uno u otro sistema tuvo para la vida económica de las sociedades matrimoniales, se han realizado diversas valoraciones. Con frecuencia se interpreta como rasgo fundamental del régimen dotal el hecho de que, al permanecer en privativo de uno de los cónyuges

de Valencia. Valencia, 1992. Este último centrado en el área de la que esta investigación se ocupa. Representante del interés de la antropología por las relaciones matrimoniales y la evolución de sus formas durante el periodo medieval es GOODY, J.:La evolución de la familia y el matrimonio. Universitat de València. Valencia, 2009.

${ }^{6}$ GOODY, J.: Op. Cit. Pp. 243 y ss.

7 Han sido numerosas y muy diversas las interpretaciones que sobre el origen de esta figura legal se han hecho, citamos dos como las más representativas, por una parte BELDA SOLER, M.A.: El régimen matrimonial de bienes en los Furs de Valencia. Ed. Cosmos. Valencia, 1966 quien considera el origen autóctono de este sistema y por otra MORÁN MARTÍN, R.: Materiales para un curso de Historia del Derecho Español. T. II. UNED. Madrid, 2000 Pp 66 y ss. quien apunta al origen germánico de este tipo de comunidad de bienes. 
gran parte del patrimonio de la pareja, se producía una situación de inmovilización de esa parte de los bienes, de forma que quedaba limitada su disponibilidad para arriesgarlo en inversiones productivas o especulativas que pudieran proyectarse por el esposo, o incluso por ambos cónyuges. Otra lectura de la misma situación, consecuencia en este caso de la observación de documentación notarial, indica que en numerosas ocasiones, el hecho de haber optado por el régimen dotal permitió la salvaguarda de los bienes de la pareja ante situaciones de deudas del esposo, al quedar los bienes familiares integrados en el patrimonio privativo de la esposa, lo que hacía imposible su traba y enajenación por los acreedores, quienes perseguían legalmente las deudas generadas por el esposo. Esta ventaja sustancial del régimen dotal sobre la comunidad de bienes ha sido señalada por diversos autores, resultando muy visible el efecto disgregador de los patrimonios familiares que tuvo, en determinadas y muy concretas circunstancias, el régimen de comunidad de bienes ${ }^{8}$.

En nuestra opinión, ambas interpretaciones sobre las consecuencias económicas de la opción por el régimen dotal son perfectamente válidas y compatibles. Únicamente debemos tener en cuenta sobre qué sector o clase social se realiza la observación. Entre los estratos superiores de la sociedad el hecho de casar acogiéndose a este régimen obedece a una estrategia de ascenso social de los maridos, quienes han de ver cómo sus nuevos parientes por afinidad tratan de mantener bajo cierto grado de control la parte de bienes, frecuentemente inmuebles, que constituyen patrimonio privativo de las mujeres de su familia. En el caso de las parejas de artesanos o pequeños propietarios agrícolas resultaba ventajoso optar por el régimen dotal si se preveían posibles circunstancias adversas que pudieran hacer peligrar los bienes de producción con los que se mantenía la unidad familiar ya que la ficción de la titularidad femenina de los mismos podía preservarlos de la persecución de los acreedores. Éste fue, con toda probabilidad, el principal motivo de la aceptación del sistema dotal en la sociedad valenciana y especialmente desde el s. XVI, donde los niveles de endeudamiento en todas las capas sociales fueron alarmantemente altos, extendiéndose la realidad de quiebra económica a todo el reino en una situación general de crisis ya en el s. XVII.

Si bien, como vemos, existen reflexiones y diversas interpretaciones sobre las consecuencias que para las parejas tuvo la opción por uno u otro régimen económico del matrimonio, no se han llevado a cabo trabajos pormenorizados que valoren o cuantifiquen la elección de régimen económico matrimonial en sectores so-

${ }^{8}$ GUILLOT ALIAGA, D.: Op. Cit. y para el ámbito geográfico del que se ocupa este trabajo, ver TORRÓ GIL, LL.: La reial fàbrica de draps d'Alcoi. Ordenances gremials. (segles XVI al XVIII). Ayuntamiento de Alcoy e Institut de Cultura «Juan Gil-Albert». Alcoy, 1996.Pp 18 y 33. Donde el autor menciona este efecto disgregador de la "germania» observable en las "composicions» o sanciones económicas con que la Corona castigó a amplias capas de la sociedad alcoyana del s. XVI por su apoyo a la revuelta y guerra de las "Germanias" ya que a pesar de acusarse formalmente a los varones, se ejecutan los patrimonios conyugales al encontrarse casados en régimen de comunidad de bienes la mayor parte de los castigados. 
ciales o geográficos concretos, dándose generalmente como válida la preferencia por el sistema dotal para todo el reino y durante todo el periodo medieval.

Existe una amplia bibliografía de investigaciones realizadas sobre los matrimonios que se contrajeron bajo el régimen dotal en el ámbito del reino de Valencia, especialmente abundante para fechas posteriores a $1500^{\circ}$. No se han realizado trabajos representativos que estudien la realidad de la aplicación de la norma foral sobre la organización económica del matrimonio para fechas anteriores al s. XVI. Falta un estudio completo de un periodo de más de dos siglos de evolución del reino de Valencia, los que van desde la conquista cristiana y la pronta implantación del cuerpo más antiguo de disposiciones forales, en 1261, hasta la primera mitad del s.XVI. Este hecho, unido a la existencia de documentación notarial relativamente abundante para el periodo bajo-medieval en determinadas zonas del reino, circunscribió la investigación que presentamos al área geográfica que hemos mencionado anteriormente, centrándose los parámetros temporales en el lapso que va desde 1421 a 1531, en razón de la disponibilidad de fuentes consultables para ese periodo.

Respecto de las principales características de esta área geográfica, debemos destacar tres que, a nuestro juicio, resultan determinantes en los resultados de la investigación. La primera consiste en la relativamente tardía incorporación de estos territorios al nuevo reino que Jaime I estaba organizando en el s. XIII en Valencia. La presencia y titularidad cristiana de esta zona data de 1245, con la llegada de los efectivos feudales a la línea imaginaria que uniría la localidad de Biar, al oeste, con Busot, en la costa alicantina; quedando la extensa zona montañosa del norte de la actual provincia de Alicante bajo dominio más nominativo que efectivo de la Corona, un área que, encontrándose poblada por mudéjares autóctonos y por contingentes de desplazados en años anteriores por la expansión cristiana, presentó oposición armada a los nuevos dueños del territorio, creándose una situación de casi permanente conflicto que no se estabilizará militarmente hasta 1305 tras dos guerras que posibilitaron finalmente el total control feudal de los territorios objeto de esta investigación ${ }^{10}$.

Esta situación se tradujo para los colonos que inicialmente se establecieron en estas comarcas tras los llamamientos de la Corona, en un clima de inseguridad casi permanente. Habitar en estos territorios de la frontera sur valenciana durante la segunda mitad del s. XIII supuso la aceptación de riesgos físicos para las personas y las propiedades en mucha mayor medida que en otras áreas fronterizas peninsulares, debido a la prolongada resistencia mudéjar ante la presencia feudal.

9 BAIXAULI, A.: Casar-se a l'Antic Règim. Dona i familia a la València del segle XVII. Universitat de València. Valencia, 2003. Es, junto a los ya citados de GUILLOT ALIAGA, D. y BELDA SOLER, M.A. uno de los diversos trabajos representativos del interés que ha despertado la regulación matrimonial foral valenciana; debemos señalar que todos ellos se centran en la Edad Moderna.

10 Sobre el devenir de los territorios del norte alicantino desde la presencia cristiana hasta la consolidación del dominio feudal, véase TORRÓ ABAD, J.: El naixement d'una colònia. Diputación de Alicante y Universidad de Valencia. Valencia, 1999. 
Estos riesgos fueron integrados en la economía de las comunidades cristianas de la zona mediante algunas modificaciones de las actividades productivas, buscando aprovechar las oportunidades que la situación brindaba. Se esperaba, teóricamente que los colonos tomaran posesión de las parcelas agrarias que se les asignaban mediante la institución del «Repartiment» y las cultivaran, generando riqueza con la que hacer posible el pago de impuestos o de rentas feudales y fijando las bases para la necesaria reproducción vegetativa de los efectivos cristianos. En la realidad, los nuevos pobladores hicieron gala de una movilidad más que notable. Muchos vendieron rápidamente sus propiedades agrícolas y otros adoptaron una economía dual, atendiendo durante una parte del año las labores del campo y empleando el tiempo restante en el pillaje organizado y la captura de bienes y personas del bando vencido, mediante la creación de compañías de irregulares que aprovecharon el desorden general. Sólo en los años finales del s. XIII se estabilizará el poblamiento cristiano de esta zona ${ }^{11}$.

Este clima de inestabilidad, prolongado en el tiempo durante años, modificó y condicionó el establecimiento de actividades económicas a la vez que, como creemos, se halla en el origen del predominio que presenta en estas comarcas la "germania» como sistema matrimonial preferido frente al régimen dotal.

La segunda característica de las localidades aquí estudiadas, y que consideramos significativa, está relacionada con la titularidad jurídica, predominantemente real, de las ciudades y sus espacios agrarios en esta zona, siendo, como por otra parte fue la norma en Valencia, minoritarios y de menor relevancia económica los señoríos privados. Esta circunstancia trasladada a las localidades objeto de este estudio, significa que la mayoría de los centros urbanos tuvieron durante la mayor parte del s. XV un régimen jurídico-fiscal y representativo de titularidad real; por lo tanto y siempre en términos generales, un régimen más franquiciado y más favorable al establecimiento de personas y actividades económicas, como fue el caso de Alcoy o Bocairent; Cocentaina por su parte, muy cercana a Alcoy, constituye el ejemplo de villa de señorío privado más importante del área.

Finalmente, el tercer rasgo particular que se debe tener en cuenta en la caracterización de la zona objeto de esta investigación es su temprana vocación económica por la manufactura textil, y el éxito de esta actividad a pesar del drenaje relativo de recursos que representaron la renta feudal o los impuestos de la Corona, dependiendo del caso ${ }^{12}$. Como resultado de un conjunto de condicionantes sobre los que diversos autores se han interesado ${ }^{13}$ y que, básicamente, se resumen en suelos de escasa vocación agrícola, existencia de una numerosa ganadería lanar

11 TORRÓ ABAD, J.: La formació d'un espai feudal. Alcoi de 1245 a 1305. Valencia. Diputación de Valencia, 1992. Pp. 188-241.

12 Sobre la fiscalidad general en los territorios del sur valenciano durante el periodo medieval; MIRA JÓDAR, A.J.: Entre la renta y el impuesto. Fiscalidad, finanzas y crecimiento económico en las villas reales del sur valenciano (siglos XIV-XVI). PUV. Valencia, 2005.

${ }_{13}$ Destacamos el trabajo realizado sobre la configuración de la actividad textil alcoyana por TORRÓ GIL, LL.: Op.Cit. 
y gran cantidad de cursos de agua aprovechables mediante el establecimiento de molinos hidráulicos. Estos condicionantes se hallan en el origen de la implantación y su posterior desarrollo, desde el s. XIV de la actividad manufacturera textil que se organizó mediante el sistema gremial, que tuvo carácter predominantemente urbano y que con posterioridad, evolucionó hacia la constitución de compañías que controlaron las diversas fases de la producción, así como la comercialización de los tejidos acabados. La especialmente favorable dotación de estos territorios y, en particular de la ciudad y término de Alcoy, para el desarrollo de la actividad textil, se tradujo en una extensa implantación del negocio y su evolución hacia el comercio, que presentó un marcado carácter exportador en el s. XV y primeros años del XVI, momento histórico que coincide con el periodo observado en este trabajo. Estas circunstancias pueden encontrase, junto a otras causas, en el origen del hecho de que la crisis demográfica y económica que se observa en el resto del reino valenciano durante el s. XV, no se aprecia en esta zona que, con altibajos, ve crecer sus efectivos de población durante todo el siglo ${ }^{14}$.

\section{METODOLOGÍA Y RESULTADOS}

Establecidos los propósitos generales de la investigación, resultó imprescindible la consulta de unos tipos determinados de documentos de aplicación del derecho, lo que fue posible gracias a la existencia de fondos relativamente abundantes de documentación para el periodo y las localidades estudiadas. El proceso de consulta de los documentos originales ha tenido como base material 62 protocolos notariales, además de un notal y un índice anual o «baldufari» conservados en diversos archivos. Los responsables de todo este cuerpo documental fueron 28 notarios no especializados, que dieron forma y recogieron todo tipo de actos jurídicos privados en el área estudiada en el periodo que va de 1421 a 1531, momento en que las tipologías notariales presentan en el conjunto del reino una homogeneidad formal notable, gracias, entre otros factores, a la difusión de los formularios entre los profesionales. El tipo documental que ha proporcionado la mayor parte de la información sistematizada en este trabajo ha sido el contrato nupcial en cualquiera de sus dos opciones, dotal o en comunidad de bienes. Este conjunto de documentos, además de informar sobre el régimen económico al que se acogían los actuantes en su nueva sociedad, proporciona datos como los nombres, el lugar de origen y la filiación de los contrayentes, además de valiosa información sobre el nivel socio profesional de los cónyuges y sus progenitores. Inmediatamente anteriores a los contratos matrimoniales, se anotaron en numerosas ocasiones las donaciones que las familias realizaban a favor de las nuevas parejas. Estas aportaciones adoptaron con frecuencia la forma de «donatio inter vivos», y su valor ra-

\footnotetext{
${ }^{14} \mathrm{El}$ análisis demográfico «clásico» sobre el conjunto del reino valenciano y, específicamente sobre los territorios del sur se halla en FURIÓ, A.: Història del País Valencià. Pp. 11 a 243. Generalitat Valenciana. Valencia, 1995.
} 
dica en el hecho de que ilustran las estrategias y los acuerdos entre los parientes de los novios ante las uniones matrimoniales, además de proporcionar datos cuantificables de tipo económico.

Un grupo diverso de documentación contenida en los protocolos notariales, y que también ha sido recogido para este trabajo, se halla constituido por actos jurídicos de diversa intención, como liquidaciones de cuentas sobre bienes en usufructo, documentos de constitución de tutela de menores, compraventas, inventarios de bienes vinculados a procedimientos de tutela, reconocimientos de deuda u operaciones de crédito, documentos de últimas voluntades de diversos tipos, recibos de pago del «creix» del esposo en matrimonios en régimen dotal, etc. Esta documentación diversa tiene como denominador común proporcionar información sobre el régimen económico matrimonial al que se acogieron los diversos actuantes, quienes aportan este dato ante el notario a la hora de formalizar sus negocios jurídicos. Finalmente, se completa el conjunto de documentación estudiada con 94 testamentos y codicilos que han resultado especialmente útiles en la verificación de las consecuencias que la elección de uno u otro régimen económico en el matrimonio tiene sobre la aplicación práctica del derecho de sucesiones.

En total, se han estudiado 544 documentos originales para la realización de este trabajo, sistematizándose en una base de datos que proporciona los valores estadísticos y que ofrece las cuantificaciones en valores absolutos y porcentuales. De ese conjunto de valoraciones reseñamos a continuación los resultados generales más relevantes que, junto a observaciones más específicas y reducidas, describen una realidad social claramente diferenciada respecto del resto de territorios del reino medieval de Valencia.

La documentación analizada proporciona un dato de importancia capital para la globalidad del periodo estudiado, obtenido teniendo en cuenta exclusivamente los contratos nupciales en sentido estricto, que indica para la zona meridional del reino de Valencia un predominio muy notable del modelo de matrimonio en comunidad de bienes respecto del dotal que, en principio, y como se ha mencionado anteriormente, se presenta favorecido por la legislación entonces vigente

TABLA 1

\begin{tabular}{|l|l|l|}
\hline \multicolumn{3}{|c|}{ PORCENTAJES DE TIPO DE CONTRATOS NUPCIALES } \\
\hline Germanía & 296 & $84,11 \%$ \\
\hline Dotal & 53 & $15,18 \%$ \\
\hline
\end{tabular}

Estos valores se distribuyen entre las diferentes localidades que integran el estudio de la siguiente forma: 
TABLA 2

\begin{tabular}{|l|c|c|c|}
\hline \multicolumn{4}{|c|}{ DISTRIBUCIÓN GEOGRÁFICA } \\
\hline & Total & Germanía & Dotal \\
\hline Alcoi & 239 & $88,28 \%$ & $11,71 \%$ \\
\hline Bocairent-Banyeres & 39 & $94,87 \%$ & $5,12 \%$ \\
\hline Cocentaina & 27 & $51,85 \%$ & $48,14 \%$ \\
\hline Otros & 44 & $77,27 \%$ & $22,72 \%$ \\
\hline
\end{tabular}

Los datos indican un comportamiento diferenciado respecto de la zona mejor estudiada del reino, la ciudad de Valencia y su entorno inmediato, donde todos los autores que en algún momento se han ocupado del fenómeno nupcial coinciden en señalar un predominio absoluto del modelo dotal para todo el periodo medieval ${ }^{15}$. Aunque la tabla n. ${ }^{\circ} 1$ resulta la más significativa de la investigación ya que muestra la preferencia generalizada hacia un modelo de régimen económico matrimonial que se presupone en franca regresión en el periodo histórico que nos ocupa, existen una serie de resultados que ilustran comportamientos vinculados a esta situación y que consideramos de relevancia ya que nos proporcionan información con la que explicar algunas de las razones que justifican una opción generalizada tan particular.

Uno de estos resultados es el que obtenemos si interrogamos las fuentes teniendo en cuenta el nivel socioprofesional de los contrayentes o sus familias; de esta forma podemos observar si la estratificación social que la evolución económica produjo en la sociedad estamental feudal en esta área incidió o tuvo alguna influencia sobre el modelo nupcial en lo relativo al régimen económico, para ello, y dada la circunstancia de que la documentación consultada ofrece información sobre el nivel socioprofesional del esposo y sobre el de la esposa, se ha realizado el cálculo de los porcentajes teniendo como valor de referencia el doble de la cantidad exacta de contratos de cada tipo, ya que nuestra intención es observar si el nivel de vida previo al matrimonio de ambos contrayentes tuvo incidencia y en qué medida, sobre la elección del régimen económico matrimonial, con el siguiente resultado:

${ }^{15}$ FURIÓ, A.: Camperols del País Valencià. Diputación de Valencia. Valencia, 1982. También en FURIÓ, A.: «Tierra, familia y transmisión de la propiedad en el País Valenciano durante la Baja Edad Media» en PASTOR, R.: Relaciones de poder, de producción y parentesco en la Edad Media, aproximación a su estudio. CSIC. Madrid, 1990. VERCHER I LLETÍ, S.: Casa, familia i comunitat veïnal a I'horta de València. Catarrosa durant el regnat de Ferràn el Catòlic (1479-1516) Ajuntament de Catarroja. Valencia, 1992. Pp. 51 a 71. 
TABLA 3

\begin{tabular}{|l|l|l|l|l|}
\hline & \multicolumn{2}{|c|}{ Dotal } & \multicolumn{2}{c|}{ Germania } \\
\hline Agricultor & 3 & $2,83 \%$ & 72 & $12,16 \%$ \\
\hline Labrador-arador & 2 & $1,88 \%$ & 6 & $1,01 \%$ \\
\hline Pastor & 0 & $0 \%$ & 9 & $1,52 \%$ \\
\hline Carbonero & 0 & $0 \%$ & 1 & $0,16 \%$ \\
\hline Paraire & 3 & $2,83 \%$ & 37 & $6,25 \%$ \\
\hline Tejedor & 2 & $1,88 \%$ & 8 & $1,35 \%$ \\
\hline Tejedor cuerdas & 0 & $0 \%$ & 1 & $0,16 \%$ \\
\hline Sastre & 0 & $0 \%$ & 2 & $0,33 \%$ \\
\hline Draper & 0 & $0 \%$ & 1 & $0,16 \%$ \\
\hline Sederio & 0 & $0 \%$ & 1 & $0,16 \%$ \\
\hline Tintorero & 3 & $2,83 \%$ & 0 & $0 \%$ \\
\hline Factor & 2 & $1,88 \%$ & 1 & $0,16 \%$ \\
\hline Mercator & 2 & $1,88 \%$ & 0 & $0 \%$ \\
\hline Baxador & 0 & $0 \%$ & 1 & $0,16 \%$ \\
\hline Molinero & 0 & $0 \%$ & 1 & $0,16 \%$ \\
\hline Mestre d'obra & 0 & $0 \%$ & 1 & $0,16 \%$ \\
\hline Mestre & 0 & $0 \%$ & 2 & $0,33 \%$ \\
\hline Barbero & 1 & $0,94 \%$ & 1 & $0,16 \%$ \\
\hline Spaserio & 1 & $0,94 \%$ & 1 & $0,16 \%$ \\
\hline Serrador & 0 & $0 \%$ & 1 & $0,16 \%$ \\
\hline Notario & 3 & $2,83 \%$ & 1 & $0,16 \%$ \\
\hline Fuster & 0 & $0 \%$ & 1 & $0,16 \%$ \\
\hline Batlle & 0 & $0 \%$ & 1 & $0,16 \%$ \\
\hline Noble & 7 & $6,6 \%$ & 1 & $0,16 \%$ \\
\hline Honorable & 6 & $5,66 \%$ & 9 & $1,52 \%$ \\
\hline & & & 1 &
\end{tabular}

Se han realizado en esta tabla tres divisiones por sectores productivos, con un cuerpo central dedicado exclusivamente a las profesiones vinculadas directamente con la actividad textil, por ser ésta la que capitalizó las transformaciones económicas del periodo bajo-medieval en estos territorios, debiéndose señalar que existió una gran diversidad de situaciones y niveles de renta dentro de cada sector. Se completa la estadística con un apartado final para los miembros de las clases dirigentes de la sociedad, ya sean cargos de la administración real, local o nobles («Batlle» o representante de la Corona en las villas de titularidad real, «Honorable» o miembro de la representación ciudadana en las villas reales y también para los individuos pertenecientes a la nobleza y titulares de alguno de los señoríos de la 
zona). El resultado es claro: a mayor nivel de renta o relevancia social, menor preferencia por la comunidad de bienes y mayor decantación por el sistema dotal ${ }^{16}$. Esto no significa que entre el conjunto de personas ocupadas en el sector textil o en otros, no se dieran casos de patrimonios presumiblemente cuantiosos, tal y como parecen apuntar los valores que presentan profesiones como los tintoreros o los «paraires», que justificarían en algunos casos la elección del sistema de dote, o que entre los estamentos privilegiados no se produjeran casos de matrimonios en «fraternitat» 0 "germanía».

La situación de las viudas tras el fallecimiento de su primer esposo implicaba cierto grado de libertad, al haber recibido la propiedad o el usufructo, dependiendo de los casos, de los bienes del difunto marido. A la vez, esta situación conllevaba cierto grado de inseguridad en los casos de economías más débiles, lo que aconsejó en numerosas ocasiones el planteamiento de una nueva unión como alternativa al paso a la vida en alguna institución eclesiástica, ingresando en un convento, que fue otro de los caminos que emprendieron numerosas viudas. Esta vuelta a la situación de casadas se realizó, para las áreas estudiadas por otros autores en el ámbito valenciano y que hemos mencionado anteriormente, siempre bajo el régimen dotal, ya que permitía a la casada en segundas nupcias mantener el control sobre su patrimonio personal y el heredado de su primer matrimonio. De acuerdo con los datos que hemos obtenido de los documentos consultados, el resultado de los matrimonios en segundas y sucesivas nupcias en la zona que nos interesa es el siguiente:

TABLA 4

\begin{tabular}{|c|c|c|c|c|}
\hline \multicolumn{5}{|c|}{ MATRIMONIOS DE VIUDAS } \\
\hline & Germanía & & Dotal & \\
\hline Alcoi & 8 & & 2 & \\
\hline Bocairent-Banyeres & 1 & & 0 & \\
\hline Cocentaina & 0 & & 0 & \\
\hline Otros & 1 & & 3 & \\
\hline Total & 10 & $66,6 \%$ & 5 & $33,3 \%$ \\
\hline
\end{tabular}

16 Resulta en este sentido significativa la trayectoria familiar de Gaspar de la Ronda, señor de Benilloba y Relleu (dos pequeños señoríos muy cercanos a Alcoy); el 20 de enero de 1466 casó en régimen dotal con Damiata, de quien solo sabemos que era viuda y no era hija de familia noble (20-I-1466. Arxiu Històric Municipal d’Alcoi. Protocolo de Pere Martí);el 27 de enero de 1494 casó a su hija Elionor en «germania» con Joan Castelló, de Alcoy (27-l-1494. Arxiu Històric Municipal d'Alcoi. Protocolo de Pere Benavent) y el 28 de diciembre de 1502, consiguió casar a otra hija, Jerónima, por el régimen dotal con un noble, Francisco Pérez de Nilla (28-XII-1502. Arxiu Històric Municipal d’Alcoi. Protocolo de Pere Benavent). Se observa la tendencia propia de una familia del grupo privilegiado a casar en régimen dotal, aunque, y esto es lo significativo de este caso, en la unión de una de sus hijas precisamente con un alcoyano, se optó por el régimen de comunidad de bienes. 
Se repite en este caso, aunque con menor intensidad que en las primeras nupcias, el comportamiento decantado hacia la comunidad de bienes incluso en matrimonios en los que la esposa aportó, con toda probabilidad, patrimonio más importante que el del nuevo marido a la unidad conyugal, lo que representa un comportamiento muy específico entre un colectivo de mujeres que podían optar teóricamente por un modelo económico matrimonial más conservador respecto de sus bienes pero que, en la práctica, aportaron mayoritariamente sus patrimonios a sociedades conyugales en comunidad de bienes donde ellas eran solo una parte de la dirección de las mismas ${ }^{17}$.

El conjunto presenta recurrentemente la preferencia generalizada por la comunidad de bienes entre las parejas de esta área, debiéndose significar que esta tendencia es más acusada entre las parejas urbanas que entre las que casan en pequeñas localidades que tienen la actividad agropecuaria como medio principal de vida. También se observan mayores porcentajes de parejas que casan en comunidad de bienes en las villas de titularidad real que en las de señorío, donde aumenta el número de matrimonios contraídos en régimen dotal, sin llegar nunca a ser mayoritario, dentro del periodo estudiado.

Establecida por la persistencia de los valores estadísticos, la opción mayoritaria del sistema de comunidad de bienes entre las parejas estudiadas experimenta cierta evolución temporal, que se resume en la tabla $n .^{\circ} 5$. Consiste esta en una perceptible modificación de los valores entre las dos opciones de régimen económico en el matrimonio, desde unos porcentajes casi absolutos a favor de la comunidad de bienes en los años más tempranos observados en esta investigación, a una significativa disminución de las diferencias en los años finales del lapso temporal observado que, recordamos va desde 1421 a 1531, evolución que, de constatarse su prolongación en el tiempo, acabaría modificando con toda probabilidad la situación general, entrada ya la Edad Moderna.

TABLA 5

\begin{tabular}{|l|l|l|l|}
\hline \multicolumn{4}{|c|}{ EVOLUCIÓN TEMPORAL DE CONTRATOS MATRIMONIALES } \\
\hline & $\begin{array}{l}\text { Total contratos hasta } \\
\mathbf{3 1 - 1 2 - 1 4 7 0}\end{array}$ & Germanías & Dotales \\
\hline Alcoi & 41 & $38-92,68 \%$ & $3-7,31 \%$ \\
\hline Bocairent-Banyeres & 7 & $7-100 \%$ & $0-0 \%$ \\
\hline Cocentaina & 1 & $1-100 \%$ & $0-0 \%$ \\
\hline Otros & 16 & $13-81,25 \%$ & $3-18,75 \%$ \\
\hline
\end{tabular}

17 Es revelador del interés de las viudas en contraer rápidamente matrimonio, aun en el caso de no tener una mala situación económica, el hecho de que entre este colectivo se da la más alta tasa de movilidad detectable en los contratos matrimoniales, ya que el $33,33 \%$ de las viudas observadas en este trabajo cambia de domicilio cuando contrae sus segundas nupcias 
TABLA 5 (Continuación)

\begin{tabular}{|l|l|l|l|}
\hline \multicolumn{3}{|c|}{ EVOLUCIÓN TEMPORAL DE CONTRATOS MATRIMONIALES } \\
\hline & $\begin{array}{l}\text { Total contratos desde } \\
1-1-1471\end{array}$ & Germanías & Dotales \\
\hline Alcoi & 198 & $173-87,37 \%$ & $25-12,62 \%$ \\
\hline Bocairent-Banyeres & 32 & $30-93,75 \%$ & $2-6,25 \%$ \\
\hline Cocentaina & 26 & $13-50 \%$ & $13-50 \%$ \\
\hline Otros & 28 & $21-75 \%$ & $7-25 \%$ \\
\hline
\end{tabular}

En el resumen de resultados presentado existen tres aspectos que consideramos claves para realizar una lectura que permita la explicación de un comportamiento nupcial tan particular en la sociedad estudiada. Los tres sugieren la conexión entre la elección del sistema matrimonial y las actividades económicas. Por una parte resulta significativo cierto carácter urbano de la opción por la comunidad de bienes. A ello hay que sumar el hecho de que donde esta opción se presenta con mayor intensidad es en las ciudades de titularidad real. Este régimen jurídico, muy extendido en el reino valenciano, implicaba la constitución de órganos de representación y gobierno que permitieron la intervención en los asuntos ciudadanos de las oligarquías locales procedentes de estamentos no privilegiados, a la vez que, en términos generales, un tratamiento fiscal más favorable al establecimiento de personas y actividades productivas que en las localidades de señorío o titularidad privada. El tercer punto que resulta clave en nuestra interpretación radica en la vinculación entre niveles socio profesionales y régimen económico del matrimonio y, más concretamente, en la relación existente entre la actividad económica y la opción por uno u otro sistema matrimonial.

Gracias a las investigaciones realizadas por diversos autores, conocemos en la actualidad con cierta precisión las actividades económicas que constituyeron el centro de la vida urbana en las ciudades del reino medieval de Valencia. Para el caso del área sur de Valencia y norte de la actual provincia de Alicante se han perfilado, básicamente mediante investigaciones realizadas sobre la fiscalidad aunque también por otros medios, cuáles fueron para el $\mathrm{s}$. XV las actividades productivas predominantes ${ }^{18}$, resultando, como es notorio, que la manufactura textil gozó de una temprana e intensa implantación en estos territorios del sur valenciano, desde el s. XIV con constancia escrita, aunque posiblemente ya existiera de forma organizada con anterioridad, y que esta actividad fue determinante en el desarrollo económico de estas comarcas hasta bien entrada la Edad Moderna.

Lo interesante para el asunto que nos ocupa es, no solamente constatar la extensión de este sector productivo, que entendemos se halla en el origen de la co-

18 MIRA JÓDAR, A.J.: Entre la renta y el impuesto. Fiscalidad, finanzas y crecimiento económico en las villas reales del sur valenciano (siglos XIV-XVI). PUV. Valencia, 2005. 
rriente migratoria desde las pequeñas localidades cercanas hacia los centros urbanos como Alcoy y Bocairent ${ }^{19}$, sino comprender la estructura de sus procedimientos de producción, ya que el sistema de elaboración de una pieza textil requiere de una secuencia de tareas diferenciadas, desde el lavado de las lanas, cardado, peinado, emborronado, hilado, urdido, batanado, teñido, tirado, cortado y nivelado ${ }^{20}$. Esta diversidad de tareas requirió el establecimiento de una serie de obradores o talleres urbanos, en los que empresas artesanas de tipo familiar en las que podemos intuir como fundamental el trabajo de la mujer, llevaban a cabo determinados procesos sobre las piezas textiles en los que se hallaban especializadas. De esta forma, el producto iba siendo trasladado físicamente hasta llegar al punto donde se liquidaban las tasas fiscales que lo gravaban ${ }^{21}$ y se procedía a su comercialización, en los mercados locales inicialmente y a través de la exportación a mercados de medio y largo radio ya en la segunda mitad del s. XV ${ }^{22}$. Este sistema descentralizado implicó el concurso de la mayoría de la población urbana, embarcada en una empresa común dirigida inicialmente por el sector de los tintoreros y, posteriormente por los «paraires», quienes organizaron las diferentes fases de la producción. ${ }^{23}$

La evolución de este sistema en el tiempo hacia la concentración de capital fue relativamente rápida, y se produjo al acceder el gremio de «paraires» al control de la comercialización del producto final, lo que les permitió, desde su posición dominante, estrechar los márgenes de beneficio al resto de participantes en la producción, situación que se hace patente en Alcoy, el mayor centro manufacturero de la zona, desde la década de 1470. La documentación estudiada deja constancia de que los «paraires» más relevantes de la localidad actuaron como mercaderes en operaciones de ventas de largo alcance y también como acreedores en operaciones de crédito, superando ampliamente las funciones que en principio cumplían en el proceso de elaboración, esto es, la compra de las lanas, su cardado y secado.

\section{CONCLUSIONES}

De acuerdo con los datos anteriormente expuestos, podemos sintetizar los resultados principales de esta investigación para el área geográfica estudiada en seis puntos principales:

19 Sirva como valor general para todas las localidades objeto de este trabajo una tasa de inmigración del $19,77 \%$ obtenida mediante la cuantificación del número de parejas que cambian de localidad al contraer matrimonio.

20 TORRÓ GIL, LL.: Op. Cit. Pp. 38 a 40.

21 El «Tall del drap», TORRÓ GIL, LL.: Op. Cit. P. 36.

22 Tal y como indica la presencia de mercaderes en la zona, especialmente en la segunda mitad del siglo XV, P. ej. en el protocolo de Bernat Candela 1495-1496, conservado en el Arxiu Municipal d'Ontinyent, actúa en diversas compraventas un mercader italiano conocido en el ámbito valenciano de la época, Conrado Dal Ponte.

${ }^{23}$ TORRÓ GIL, LL.: Op. Cit. Pp. 9 a 43. 
1. De 1421 a 1531 se aprecia como opción notablemente mayoritaria el régimen económico del matrimonio en comunidad de bienes.

2. La tendencia por la opción de casar en comunidad de bienes es más intensa en las ciudades con régimen jurídico de titularidad real y menor en las de señorío.

3. Los estamentos privilegiados de la sociedad y los grupos sociales de mayor nivel de renta optan preferentemente por el régimen dotal, mientras que el resto de la sociedad lo hace por el régimen de comunidad de bienes.

4. Se observan mayores porcentajes de uniones en comunidad de bienes entre las parejas urbanas que entre las que se crean en el medio rural, aun siendo mayoritaria esta opción en ambas situaciones.

5. La opción por la comunidad de bienes también es mayoritaria en los matrimonios contraídos en segundas nupcias (viudas), aunque presenta menor intensidad que en los valores generales.

6. Se aprecia un lento pero progresivo incremento con el paso del tiempo en el número de matrimonios contraídos en régimen dotal, con la consiguiente disminución de los realizados en comunidad de bienes.

Por todo ello, interpretamos la preferencia mayoritaria de las parejas de la zona por el régimen de comunidad de bienes como una estrategia de adaptación económica a un entorno productivo que se encontraba en franca expansión en el territorio objeto de estudio durante el s. XV. Mediante esta opción, un matrimonio recién constituido y con intención de invertir capital en el sector manufacturero textil, evitaba el potencial efecto de inmovilización que el régimen dotal podía representar sobre el patrimonio que la familia de la esposa le asignaba en el momento de contraer nupcias, y creaba un fondo común con las aportaciones de las familias de ambos cónyuges que les facilitaba su inserción en el tejido productivo urbano, o la ampliación de sus actividades, dependiendo del caso. Entendemos que la resistencia local a la norma en lo relativo al régimen económico del matrimonio, si bien no nace exclusivamente de esta particular situación productiva, ya que la figura legal de la "germanía»o «fraternitat» está documentada en la zona con anterioridad a las fechas de este trabajo, sí explica su extensión entre el conjunto de la sociedad cristiana, así como su pervivencia en el tiempo, por presentar el régimen de comunidad de bienes ventajas concretas sobre el sistema dotal, ya que se adaptaba mejor al establecimiento de pequeñas unidades productivas de tipo familiar donde resultaba fundamental la colaboración de ambos cónyuges en los procesos productivos, representando además un sistema claro y simple en la constitución de la sociedad conyugal, y en consecuencia, en lo relativo al derecho de sucesiones.

Existieron otras zonas en el reino de Valencia donde se dieron circunstancias productivas aparentemente similares, pero solo aparentemente. La más significa- 
tiva de ellas es la misma ciudad de Valencia, donde esta preferencia por el régimen de «germanía» no se produjo, al contrario, se ha interpretado tradicionalmente que el sistema dotal resultó determinante en el desarrollo de las actividades de la burguesía mercantil valenciana, al igual que en otros territorios de la Corona de Aragón.

A este respecto debemos puntualizar que la actividad textil en la capital del reino tuvo una génesis y desarrollo bien diferentes respecto del área del sur, ya que se llevó a cabo mediante capital comercial en numerosos casos externo y ya constituido, con lo que las oportunidades de acceso al negocio en condiciones ventajosas para las familias procedentes del sector primario fueron mínimas. Participar del negocio textil en la Valencia del s.XV representaba frecuentemente el convertirse en asalariado dependiente de quien controlaba el capital, mientras que en el área alcoyana se planteó la producción, al menos durante un cierto tiempo, en forma de colaboración de pequeñas unidades productivas autónomas. Ésta es la razón fundamental de la diferencia de comportamientos en lo relativo a la persistencia del régimen de "germanía» entre la zona urbana de la ciudad de Valencia y el área del sur del reino. El área alcoyana generó una actividad manufacturera de gran relevancia con materias primas y capitales propios en un proceso acumulativo que durante largos periodos quedó abierto al acceso de aquellos que pudieran invertir su dinero y trabajo en la empresa textil, este proceso se prolongó durante siglos hasta convertir a estas comarcas en un área netamente exportadora de mercancías y generadora de crédito.

Otra realidad diferente respecto de las familias artesanas era la de las parejas que accedían al matrimonio con rentas económicas altas, bien por su pertenencia al estamento nobiliario o por formar parte de la alta burguesía ciudadana. En estos casos, las estrategias de linaje de las familias de los contrayentes, donde las aspiraciones de ascenso social de cada grupo familiar eran determinantes, primaron la opción dotal como medio de conservar cierto grado de control sobre el patrimonio que, teóricamente, se perdía por un linaje concreto al casar una de sus hijas.

En el comportamiento que ante el matrimonio presentan los diferentes sectores sociales, se aprecian algunas pautas comunes a otras zonas del mismo reino de Valencia. Así, las parejas de rentas altas suelen casar mayoritariamente en régimen dotal, como realmente fue la norma en el conjunto del reino. En cambio, la gran masa de artesanos y numerosos pequeños y medianos propietarios establecieron una estrategia matrimonial que entendemos se hallaba estrechamente vinculada con la forma concreta en que se configuró el desarrollo de la manufactura textil de la zona, especialmente la alcoyana, lo que, unido a una tradición cultural proveniente de la fase de implantación de las comunidades cristianas en el área (proveniente de la segunda mitad del s. XIII) dio origen a un comportamiento muy específico en lo nupcial. Todos los datos nos indican que la inclinación mayoritaria por este sistema fue producto de su eficacia como herramienta integradora de pa- 
trimonios de nivel medio y bajo, por lo tanto, favoreció los procesos de capitalización y fue por ello especialmente útil en un contexto económico expansivo, donde las especiales condiciones que se dieron en esta zona, permitieron la génesis y proyección de la actividad textil desde la Edad Media hacia el futuro. La preferencia por la "fraternitat»o "germanía» fue durante la Edad Media una más de las condiciones favorables que otorgaban al área alcoyana una ventaja cualitativa notable sobre otras zonas manufactureras.

\section{ANEXO: FUENTES DOCUMENTALES}

AMA: Arxiu Històric Municipal d'Alcoi.

AMO: Arxiu Municipal d'Ontinyent.

APP: Archivo de protocolos del Real Colegio del Corpus Christi. Valencia.

\begin{tabular}{|c|c|}
\hline \multicolumn{2}{|c|}{ PROTOCOLOS NOTARIALES } \\
\hline \multirow[t]{13}{*}{ Guillem Peris (APP) } & Cocentaina 1469-1470 \\
\hline & Cocentaina 1471 \\
\hline & Cocentaina 1472 \\
\hline & Cocentaina 1479 \\
\hline & Cocentaina 1479 \\
\hline & Cocentaina 1480 \\
\hline & Cocentaina 1481 \\
\hline & Cocentaina 1482 \\
\hline & Cocentaina 1483 \\
\hline & Cocentaina 1484 \\
\hline & Cocentaina y Penàguila 1485 \\
\hline & Cocentaina 1486 \\
\hline & Cocentaina 1487 \\
\hline Gaspar Vives (APP) & Biar 1502 \\
\hline Pere Ferrandis (APP) & Valencia i Castalla 1414-1417 \\
\hline Lluis Peres (APP) & Valencia, Alcoi i Castalla 1496-1497 \\
\hline Domènech Catala (APP) & Llutxent i Villahermosa del Rio. 1455-1456 \\
\hline
\end{tabular}


El régimen económico del matrimonio en la sociedad valenciana tardomedieval...

\begin{tabular}{|c|c|}
\hline \multirow[t]{13}{*}{ Pere Marti (AMA) } & Alcoi 1449-1452 \\
\hline & Alcoi 1453-1454 \\
\hline & Alcoi 1455 \\
\hline & Alcoi 1456-1459 \\
\hline & Alcoi 1460 \\
\hline & Alcoi 1463 \\
\hline & Alcoi 1466 \\
\hline & Alcoi 1467 \\
\hline & Alcoi 1469 \\
\hline & Alcoi 1470 \\
\hline & Alcoi 1471-1472 \\
\hline & Alcoi 1475 \\
\hline & Alcoi 1482-1524 \\
\hline Andreu Margarit (AMA) & Alcoi 1523-1524 \\
\hline \multirow[t]{6}{*}{ Pere Benavent (AMA) } & Alcoi, Cocentaina i Penàguila 1489-1492 \\
\hline & Alcoi, Cocentaina i Penàguila 1493-1494 \\
\hline & Alcoi, Cocentaina i Penàguila 1495-1496 \\
\hline & Alcoi, Cocentaina i Penàguila 1497-1498 \\
\hline & Alcoi, Cocentaina i Penàguila 1501-1502 \\
\hline & Alcoi, Cocentaina i Penàguila 1503-1504 \\
\hline \multirow[t]{2}{*}{ Lluis Joan Alçamora (AMA) } & Alcoi 1503 \\
\hline & Alcoi 1504 \\
\hline Francesc Joan Bodí (AMA) & Alcoi 1495-1531. Baldufari \\
\hline Jaume Olzina (AMO) & Ontinyent 1421-1424 \\
\hline \multirow[t]{2}{*}{ Genís Cerdà (AMO) } & Bocairent 1464 \\
\hline & Bocairent, Banyeres i Ontinyent 1469-1471 \\
\hline Pere Calatayud (AMO) & Bocairent 1516 \\
\hline \multirow[t]{6}{*}{ Bernat Candela (AMO) } & $\begin{array}{l}\text { Bocairent, Banyeres, Ontinyent, Simat de Valldigna } \\
1490-1495\end{array}$ \\
\hline & Bocairent 1495-1496 \\
\hline & Bocairent, Banyeres 1501-1502 \\
\hline & Bocairent, Banyeres 1505 \\
\hline & Bocairent, Banyeres 1511 \\
\hline & Bocairent 1512 \\
\hline
\end{tabular}




\begin{tabular}{|l|l|}
\hline Joan Capdevila (APP) & Penàguila 1423-1425 \\
\hline Marti Cabanes (APP) & Bocairent 1435-1441 \\
\hline Bertomeu Olzina (APP) & Bocairent 1507-1512 \\
\hline Miquel Vicent (APP) & Bocairent 1515-1517 \\
\hline Jaume Durà (APP) & Cocentaina 1504 \\
\hline Miquel Frigola (APP) & Cocentaina 1513 \\
\hline Jaume Gombau (APP) & Cocentaina 1520-1522 \\
\hline Joan del Mas (APP) & Cocentaina 1464-1465 \\
\hline Joan Merita (APP) & Cocentaina 1523 \\
\hline Pere de Montalbà (APP) & Cocentaina 1450 \\
\hline Mateu Peres (APP) & Cocentaina 1426 \\
\hline Baltasar de Ripoll (APP) & Cocentaina 1517 \\
\hline Francesc Talavera (APP) & Cocentaina 1509 \\
\hline Ramon Vidal (APP) & Cocentaina 1421-1422 \\
\hline Cortes de Justicia & Alcoi 1483 \\
\hline Gracià Margarit (AMA) &
\end{tabular}

